\section{A prosa fluída de Igor Sacramento}

Marcio FERNANDES ${ }^{1}$

SACRAMENTO, Igor. Depois da revolução, a televisão: cineastas de esquerda no jornalismo televisivo dos anos 1970. São Carlos: Pedro \& João Editores, 2011.

Uma mídia instigante sob análise, um tema polêmico posto à luz do dia também e um escritor com domínio sobre a prosa. Igor Sacramento dá as tintas do que vêm a seguir logo nos primeiros parágrafos do seu livro: 'Aqui, então, o que importa são as diferentes pressões e determinações que permitiram o ingresso daqueles cineastas na TV Globo e que também estiveram presentes no cotidiano do trabalho deles e nos documentários que dirigiram', escreve o autor na Introdução de 'Depois da revolução, a televisão: cineastas de esquerda no jornalismo televisivo dos anos 1970’, publicado pela Pedro \& João Editores (2011, 258 páginas).

Estamos falando de Eduardo Coutinho, Gustavo Dahl, João Batista de Andrade, Walter Lima Júnior e Maurice Capovilla, dentre outros cineastas que, na década em questão, adentraram pela porta frente naquela que já era a maior emissora de TV do País, a Globo, e que, hoje, é a segunda do planeta em sua categoria (só perde para a americana $\mathrm{ABC}$ ). Igor novamente aponta com precisão o que está investigando: ' $\mathrm{O}$ fato de esse contato (a contratação dos produtores) ter ocorrido na época em que a emissora carioca se consolidava como hegemônica chama a atenção. Afinal, muitos desses cineastas que passaram por lá tiveram trajetórias ligadas às questões da revolução nacional-popular no Brasil dos anos 1960, especialmente às formas de engajamento político propostos pelo Cinema Novo e pelo Centro Popular de Cultura da União Nacional dos Estudantes (CPC da UNE)'. Opa, aqui cabe dizer, aparece mais um interessante elemento nesta relação Globo-esquerdas, qual seja o Cinema Novo, uma categoria genuinamente verde-amarela que

1 Doutor em Comunicação \& Cultura pela Universidade Federal do Rio de Janeiro (UFRJ), com doutoramento-sanduíche pela Universidade de Lisboa (UL). Professor do Departamento de Comunicação Social (Decs) da Universidade Estadual do Centro-Oeste (Unicentro), Paraná. Contato: marciofernandes@unicentro.br assolou e assombrou o País nos mesmos anos 1960 e mesmo no decênio anterior.

Depois da revolução... está estruturado em cinco capítulos. No primeiro deles - Cineastas brasileiros, da revolução à televisão -, Igor discorre, por exemplo, sobre as eventuais relações sentimentais e o Cinema Novo. No segundo, chamado Um novo lugar da nacionalidade, trata de uma dualidade bastante interessante, a televisão do grotesco vs uma televisão de qualidade e em rede. A seguir, em Do Globo-Shell ao Globo Repórter, é a vez especialmente do Globo Repórter ser dissecado, investigando como se deram a incorporação, o controle e a transformação, assim como o reconhecimento, a consagração ou a execração das obras televisivas deles', pondera Igor. O deles, neste caso, é uma referência aos já mencionados cineastas de esquerda.

Enquanto isso, nos dois capítulos derradeiros, o autor demonstra zelo especial pelas obras de Eduardo Coutinho e de João Batista de Andrade. Três produtos de Coutinho são esmiuçados - Seis dias de Ouricuri (1976), Theodorico, o imperador do Sertão (1978) e Exu, uma tragédia sertaneja (1979) tratam de imagens do Sertão brasileiro. As imagens da cidade, como define Igor, estão em O caso Norte (1978) e Wilsinho Galileia (1978), ambos de João Batista.

\section{7}

\section{As epígrafes basilares}

Igor Sacramento recorre com propriedade a um recurso capaz de sintetizar, em poucas palavras, pensamentos complexos, as epígrafes. Duas delas refletem com elevada precisão a discussão que está em andamento na obra do pesquisador: logo ao começo do livro, Igor reproduz uma fala de um dos cineastas da época em questão, o qual dizia que 'negar a TV é burrice'. Estamos falando de Paulo Gil Soares, artista que está no rol dos analisados na presente prosa. Adiante, na abertura do capítulo 1, a transcrição é ainda mais interessante. Ponderou Gustavo Dahl (página 53):

Se é para fazer cultura, vamos direto à antena. Você vai encontrar certas limitações, como a presença da publicidade ou a latitude do público, mas vai realizar este lado importante que é a comunicação.

Claro que a visão de Dahl acaba por abrir caminho para uma certa superficialidade do debate, se tomarmos o que ele diz com absoluta propriedade. Felizmente, Igor vai no caminho contrário e já no capítulo inaugural apresenta, por exemplo, um panorama denso sobre o cenário cultural do País nos anos 1950 e 1960. Estão lá repercussões sobre as obras que vão de Dias Gomes e 
Gianfrancesco Guarnieri à coletânea Cinco vezes favela, de 1962, rodada pelo CPC do Rio de Janeiro e que nunca chegou ao circuito comercial. No texto, há igualmente uma interessante informação rememorada: Cabra marcado para morrer, produto que chegou ao mercado em 1984, havia sido iniciado vinte anos antes.

Além de apresentar o panorama no capítulo em questão, Igor acaba apimentando a discussão quando escreve que Glauber Rocha, em boa escala, também esteve no cerne da chamada Indústria Cultural em determinado tempo. Estética da fome, de 1965, ajudou a transformar uma questão social relevante - fome no Brasil - em produto da Indústria Cultural, em espetáculo. O texto de Glauber, na sequência, serviria como uma das referências para Capovilla elaborar a película $\mathrm{O}$ profeta da fome, destacado inclusive fora das terras verde-amarelas - representou o Brasil no Festival de Cinema de Berlim em 1970.

$\mathrm{Na}$ continuidade da sua prosa, Igor investe em mais uma questão crucial para as reflexões a que se propôs, a dualidade TV vs esquerda. Pondera ele que a TV Globo, ao contratar cineastas de esquerda, acaba por se livrar de parte da influência da produção e capital estrangeiros, enquanto os diretores, como bem ponderara Dahl, ganham uma plateia até então dificilmente disponível para suas obras. É o binômio televisão fabril vs cinema artesanal, a bem da verdade uma discussão interminável sobre quem tem razão acerca de qual é o melhor (se é que isso se torna possível em dado momento). Nesta altura do livro, Igor demonstra com força mais uma qualidade, qual seja a capacidade de articular suas visões de mundo com as posições de outros pensadores, como Renato Ortiz, Fedric Jameson ou Raymond Williams, dentre tantos.

Sim, ao contrário do que costuma acontecer em muitos casos de livros originados de dissertações de Mestrado ou teses de Doutorado, Igor não escorrega em uma prosa prolixa, recheada de citações que, na maioria das vezes, servem apenas para mostrar que o investigador leu muito e, portanto, demonstrando uma pseudo-sapiência. Metódico, o autor de Depois da revolução... entrega ainda a seus leitores também quadros esquemáticos que produziu ao longo da sua jornada de levantamentos e que indicam a gama de conteúdos levados ao ar pela TV Globo durante 15 anos (1965-1980). Tais tabelas são também indicadoras de como ia se formando o até hoje famoso Padrão Globo de Qualidade. Em outras palavras, o livro de Igor acabará servindo de base para outros investigadores interessados em um período importante da emissora carioca. Não fosse isso suficiente, é possível se deliciar com reproduções de declarações da época que continuam a causar impacto, como o descrito à página 79, quando Igor descreve parte do processo de saída da atriz Dercy Gonçalves da TV Globo. A fonte aqui é uma edição de abril de 1980 do Jornal do Brasil, em que Dercy avalia ter sido 'jogada fora' pela Globo:

Me consumiram, me usaram enquanto não sabiam falar, não sabiam andar; naquela época a Globo era povo, precisava da prostituta que eu era, da minha arte para eles aprenderem, assim como precisaram do Chacrinha, do Longras (aquele que fazia todos os casamentos de doméstica na TV). De repente, a Globo falou: "Não quero mais ser povo, quero ser a Rainha de Sabá, xô com os brasileiros, agora vamos brincar de sociedade com eles...”.

Não deixa de ser curioso notar que, neste manto de transformação que estava revestindo em si a emissora, sobrou naquele tempo até para Chacrinha, o popular apresentador de timbre raro, visual extravagante e talento elevadamente incomum. Dispensado no final dos anos 70, voltaria triunfalmente à Globo poucos anos depois, onde ficaria como destaque aos sábados à tarde até sua morte, em 1987, no Cassino do Chacrinha.

\section{Cabra marcado para morrer e Wilsinho Galileia}

Admite-se que é na página 196 que está presente uma chave para se compreender os conteúdos disponíveis nos dois capítulos finais do livro. Ambos, como dito antes, analisam aspectos da trajetória de Eduardo Coutinho e João Batista de Andrade. Escreveu Igor:

Depois de analisar algumas contribuições de Eduardo Coutinho para o Globo Repórter, no próximo capítulo farei o mesmo com João Batista de Andrade. Com projetos diferentes dos de Coutinho, o cineasta toma a cidade como palco para a atuação de suas personagens: o migrante, o bandido, o favelado, o excluído. Não era a São Paulo dos pontos turísticos.

Sim, Igor se debruça com muitas linhas nas produções dos dois documentaristas elaboradas para a Globo mas também centra forças em outra dualidade: o Sertão tornado público por Coutinho (morto em fevereiro de 2014 e reverenciado logo a seguir na cerimônia do prêmio Oscar) e a parcela marginalizada da cidade, como bem referenciado na passagem acima. Ao narrar detalhes das cenas destas películas, Igor nos convida a um processo sinestésico intenso, já que a narrativa precisa dar conta da densidade das situações, como na histórica incomum (e trágica) de Wilsinho Galileia, morto aos 18 anos depois de dezenas de peripécias criminosas: 
"Focalizando uma foto de Wilsinho vendado, a imagem dá lugar a um plano detalhe do rosto do ator Paulo Weudes, procurando confirmar uma certa semelhança entre o intérprete e o interpretado. No começo, a feição é séria. Um sorriso debochado, enquanto brinca com sua arma, aparece para confirmar a caracterização de um indivíduo mau, frio e perverso feita pelo delegado e postas em voz off" é parte da descrição pormenorizada contida já mais ao final do livro, acompanhada de transcrições de muitos dos diálogos capturados pela sensibilidade de João Batista de Andrade, que mais tarde se tornaria um respeitado dirigente cultural e doutor em Artes Visuais.

Antes, cabe ressaltar, Igor havia dedicado boa parte da atenção dispensada ao capítulo 4 detalhando aspectos de Cabra marcado para morrer, cujo título vinha emprestado de um poema de Ferreira Gullar, de 1962, chamado João Boa-Morte. A história começara a ser gravada em 1964 e seria interrompida de modo inesperado por conta do Golpe Militar de 1964. Vinte anos depois, ao ser lançada, o público haveria de consumir uma versão um tanto pasteurizada quando comparada com a proposta original. Igor, à folha 159, anota este item, lembrando que um certo didatismo revolucionário previsto nos anos 60 havia sido posto à margem.

Pois ao apresentar esta visão panorâmica de uma das produções de Coutinho, o autor do livro aqui resenhado transparece outra qualidade enquanto pesquisador, a de apurar a multiplicidade, a pluralidade e a descontinuidade (expressões aplicadas por ele à página 249). Nada de festejos à fractalidade, à deriva, às desconexões, como sustenta logo a seguir. "Interessaram-me os acontecimentos como num todo, como partes de um todo incompletável, e, portanto, em constante processo de produção de verdades", diz. A obra de Igor Sacramento é, portanto, muito, mas muito mais do que "a presença e a atuação de cineastas de esquerda nos programas Globo-Shell Especial e Globo Repórter", conforme escreve logo no começo das conclusões da obra. Depois da revolução... é um livro completo.

Vai logo, leitor, pegar o seu exemplar. 